\title{
Carcinoma cervix with fat attenuating skull metastases
}

\author{
Anuradha Kapali', Atmakuri Sateesh Kumar ${ }^{1}$, Mukunda Malathi², S. D. Shamsundar ${ }^{3}$ \\ ${ }^{1}$ Department of Radiology, Kidwai Memorial Institute of Oncology, Bangalore 560029, India. \\ ${ }^{2}$ Department of Pathology, Kidwai Memorial Institute of Oncology, Bangalore 560029, India. \\ ${ }^{3}$ Department of Radiotherapy, Kidwai Memorial Institute of Oncology, Bangalore 560029, India.
}

Correspondence to: Dr. Anuradha Kapali, Department of Radiology, Kidwai Memorial Institute of Oncology, Bangalore 560029, India.

E-mail:kapali.anuradha@gmail.com

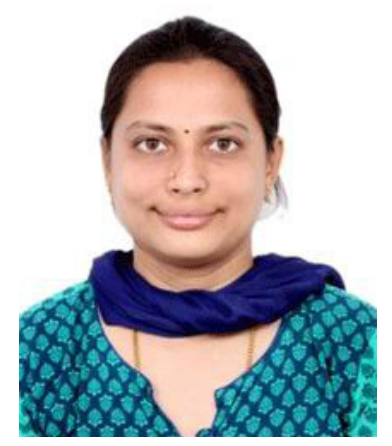

Dr. Anuradha Kapali, Assistant Professor in Department of Radiology, Kidwai Memorial Institute of Oncology, Bangalore, Karnataka, India. Special interest in oncology and women imaging.

\begin{abstract}
A B S T R A C T
Skeletal metastasis in carcinoma cervix occurs in about $0.8-23 \%$ of cases. These lesions are usually radiographically lytic. Very few cases of metastases to the skull have been identified, about 5 cases to the best of our knowledge. We present a case of adenosquamous cell carcinoma of cervix with fat attenuating skull metastases in a 38 -year-old lady that is not reported till date. The lesion was lytic, expansile and with negative attenuation of -15 to -30 Hounsfield units corresponding to fat.Metastases must be included in the differentials of scalp lesions. A history of recent onset of swelling and associated lytic areas in calvarium on contrast enhanced computed tomography with multiplicity can give a clue to metastatic nature of disease.
\end{abstract}

Key words: Carcinoma cervix; metastases; skull; fat attenuating

\section{INTRODUCTION}

Bone metastases in carcinoma cervix can be due to local extension, however, distant metastases are due to hematogenous dissemination. The metastatic sites are commonly the spine, followed by pelvic bones rarely it can involve the skull where the appearance is of an expansile lytic lesion. High index of clinical suspicion is required for the diagnosis of skull metastases and should be included in the differentials of scalp lesions in a known primary. Till date fat attenuating metastasis to skull has not been reported.

\begin{tabular}{|l|l|}
\hline \multicolumn{3}{|c|}{ Access this article online } \\
\hline Quick Response Code: & Website: \\
& http://www.jcmtjournal.com \\
\hline & \\
\hline
\end{tabular}

\section{CASE REPORT}

A38-year-old lady presented with severe neck pain for which she underwent contrast enhanced computed tomography (CECT) spine examination elsewhere that revealed multiple lytic lesions in the vertebra suggestive of metastases. She underwent biopsy of the same, which revealed metastatic adenosquamous carcinoma. The lady was diagnosed with metastases of unknown origin and referred to our institution for work up. At the time of admission the patient was bed ridden with altered sensorium. She later had one episode of vaginal bleeding for the first time according to history with

This is an open access article distributed under the terms of the Creative Commons Attribution-NonCommercial-ShareAlike 3.0 License, which allows others to remix, tweak, and build upon the work non-commercially, as long as the author is credited and the new creations are licensed under the identical terms.

For reprints contact: service@oaepublish.com

How to cite this article: Kapali A, Kumar AS, Malathi M, Shamsundar $\mathrm{SD}$. Carcinoma cervix with fat attenuating skull metastases. J Cancer Metastasis Treat 2016;2:228-30.

Received: 04-12-2015; Accepted: 17-03-2016. 


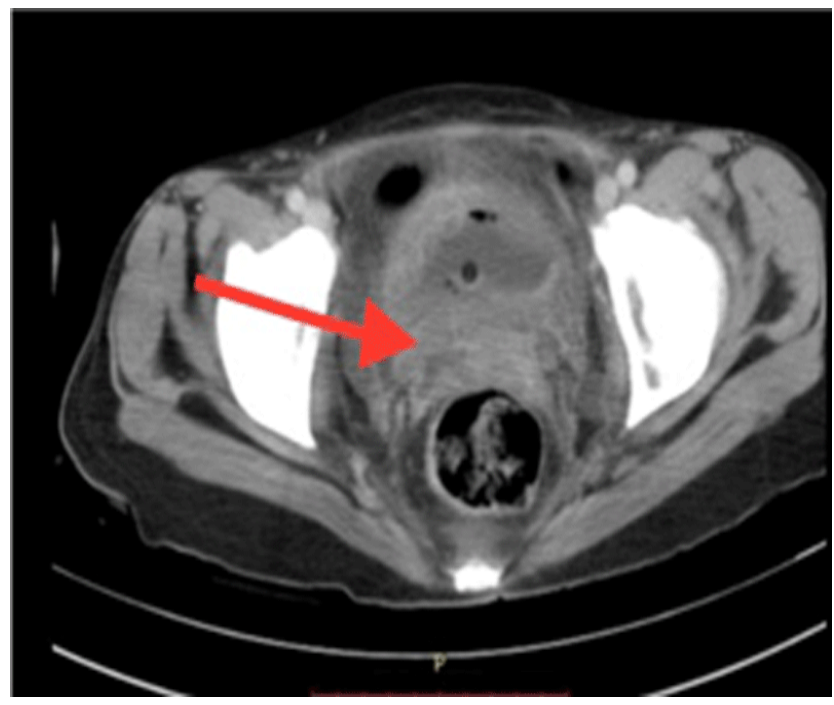

Figure 1: Heterogeneously enhancing cervical mass infiltrating the urinary bladder with bladder base thickening. Laterally parametrial stranding extends to the medial $2 / 3 \mathrm{rd}$. Fat plane with rectum is lost posteriorly. Left obturator node is seen

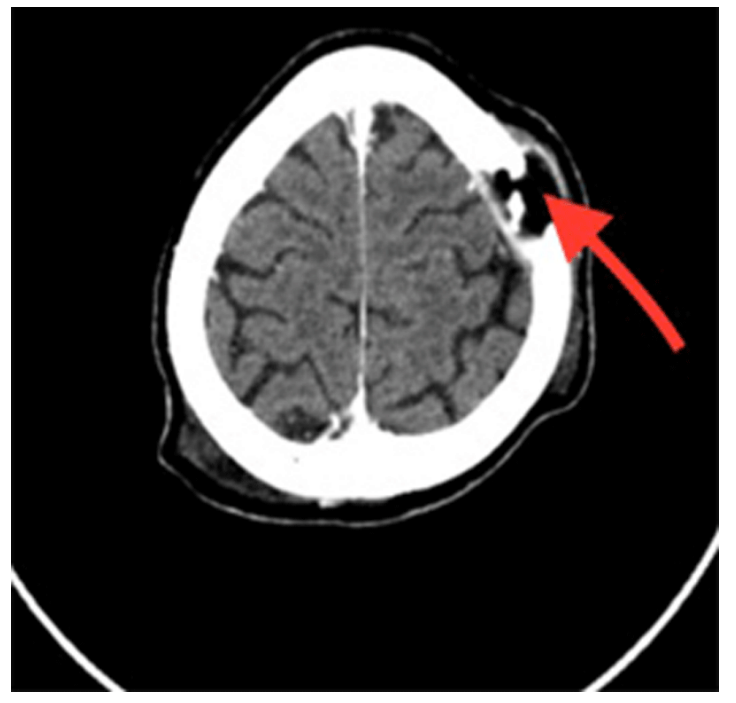

Figure 2: Expansile lytic lesion in the left frontal bone with average fat attenuation of -27 Hounsfield units (arrow tip). Underlying brain parenchyma is normal. The lesion causes corresponding scalp bulge in frontal region along the external surface
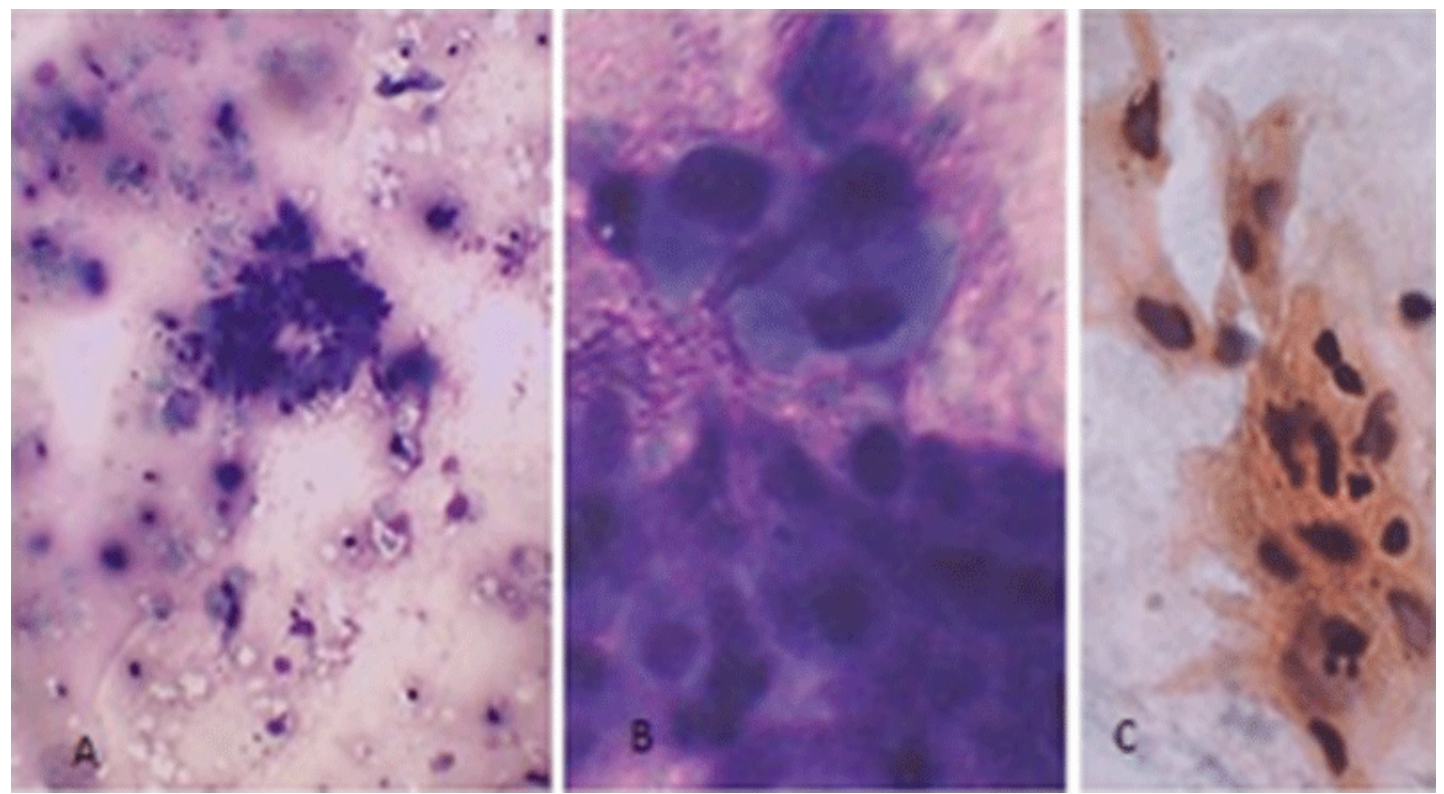

Figure 3: Photomicrograph of smear of FNAC scalp showing clusters of neoplastic squamous cells admixed with fat globules. (A) power view MGG ( $\times 100)$; (B) power view MGG (×400); (C) power view PAP (×100). FNAC: fine needle aspiration cytology; MGG: May-Grunwald Geimsa stain; PAP: papanicolaou stain

no other relevant clinical history. On general examination she had multiple soft scalp swellings, which were of recent onset, no other significant findings were present. She had a proliferative growth in the cervix measuring $3.5 \mathrm{~cm} \times 3 \mathrm{~cm}$, rest of the systemic examination was unremarkable. CECT exam of the whole body confirmed the cervical mass [Figure 1] that was infiltrating the urinary bladder. Multiple vertebral, pelvic and skull metastases were detected. The skull metastases were lytic with negative attenuation of -15 to -30 Hounsfield units [Figure 2] corresponding to fat. The metastases in spine and pelvis were of soft tissue attenuation. One of the calvarial lesions infiltrated the right transverse sinus causing thrombosis. She underwent a biopsy of cervix, which showed primary adenosquamous carcinoma. Fine needle aspiration cytology of the scalp swelling was performed which demonstrated metastatic squamous cells with presence of fat globules [Figure 3]. She had an Eastern Cooperative Oncology Group score of 4. Due to advanced nature of the disease she was treated palliatively with supportive care including intravenous fluid administration, pain management and antibiotics. There was no role of active treatment. The clinical status of the patient deteriorated rapidly and she succumbed due to the disease.

\section{DISCUSSION}

Carcinoma cervix is the most common malignancy in Indian women, with an incidence of $19-44 \%$ per 100,000 women. ${ }^{[1]}$ 
Apart from local spread, the disease spreads to the pelvic and para-aortic lymph nodes and then by hematogenous route to the supra and infradiaphragmatic viscera. ${ }^{[2]}$ About 5-35\% eventually develops pulmonary metastases, ${ }^{[3,4]} 3 \%$ develops liver metastases, ${ }^{[5]} 16 \%$ develops bone metastases. ${ }^{[4]}$

Skeletal metastasis in carcinoma cervix occurs in about $0.8-23 \%{ }^{[1]}$ of cases. Bone metastases can be due to local extension, however, distant metastases are due to hematogenous dissemination. These lesions are usually radiographically lytic, and patients have recurrent or advanced disease with other sites of metastases. ${ }^{[6]}$ The metastatic sites are commonly the spine, followed by pelvic bones. Very few cases of metastases to the skull have been identified, about five cases to the best of our knowledge.

Yanuck et al., ${ }^{[7]}$ reported a 21-year-old woman with stage IV cervical cancer that presented with a mass on the frontal bone, other cases of skull metastases reported are Niloofar Ahmadloo et al., ${ }^{[8]}$, Mohanthy et al., ${ }^{[9]}$ Abhishek et al., ${ }^{[10]}$ and Zilberlicht et al..$^{[1]}$

The case reported by Abhishek et al..$^{[10]}$ was similar to our case where the histlogical subtype was adenosquamous carcinoma and patient also had superior sagittal sinus thrombosis. Our patient had transverse sinus thrombosis. The other cases were of squamous cell carcinoma. Rath et $a{ }^{\left[{ }^{[12]}\right.}$ and Agrawal et al. ${ }^{[1]}$ reported cases with multiple metastases to the scalp (skin).

In a recent analysis of 813 patients with stage IB disease, Look et al. ${ }^{[13]}$ noted a poorer survival for patients with adenosquamous lesions. Also, more patients developed extrapelvic recurrences than those with squamous or adenocarcinoma cell types. Neuroendocrine cervical tumors and glassy cell tumors have also been associated with hematogenous spread with early-stage disease. The aggressive disease in our patient could be explained by the adenosquamous cell type of carcinoma she had.

No reports have been published till date demonstrating fat containing metastases to skull as seen in our case. The spine and pelvic metastases were not fat attenuating.

In a patient with carcinoma of cervix, metastases must be included in the differentials of scalp lesions. The lesions may mimic sebaceous cysts and lipomas (in our case, they were soft on clinical exam and fat containing on computed tomography mimicking lipoma). A history of recent onset of swelling (present in our case) should prompt imaging, associated lytic areas in calvarium on CECT with multiplicity can give a clue to metastatic nature of disease. In our patient, the disease was detected at an advanced stage as the presenting symptom itself was metastases to vertebrae presenting as neck pain she had no symptoms relating to carcinoma cervix until later.

\section{Financial support and sponsorship}

Nil.

\section{Conflicts of interest}

There are no conflicts of interest.

\section{REFERENCES}

1. Agarwal U, Dahiya P, Chauhan A, Sangwan K, Purwar P. Scalp metastasis in carcinoma of the uterine cervix--a rare entity. Gynecol Oncol 2002;87:310-2.

2. Kim RY, Weppelmann B, Salter MM, Brascho DJ. Skeletal metastasis from cancer of the uterine cervix: Frequency, patterns and radiotherapeutic significance. Int J Radiat Oncol Biol Phy 1987;13:705-8.

3. Barter JF, Soong SJ, Hatch KD, Orr JW, Shingleton HM. Diagnosis and treatment of pulmonary metastases from cervical carcinoma. Gynecol Oncol 1990;38:347-51.

4. Carlson V, Delcos L, Fletcher GH. Distant metastases in squamouscell carcinoma of the uterine cervix. Radiology 1967;88:961-6.

5. Buchsbaum HJ. Extrapelvic lymph node metastases in cervical carcinoma. Am J Obstet Gynecol 1979;133:814-24.

6. Abdul-Karim FW, Kida M, Wentz WB, Carter JR, Sorensen K, Macfee M, Zika J, Makley JT. Bone metastasis from gynecologic carcinomas: a clinicopathologic study. Gynecol Oncol 1990;39:108-14.

7. Yanuck MD, Kaufman RH, Woods KV, Adler-Storthz K. Cervical carcinoma metasatic to the skull, heart and lungs: analysis for human papillomavirus DNA. Gynecol Oncol 1991;42:94-7.

8. Ahmadloo N, Shapour O, Mansour A, Ahmad M, Mohammad M. Bony calvarium as the sole site of metastases in squamous cell carcinoma of the uterine cervix. Middle East J Cancer 2010;1:185-8.

9. Mohanty A, Dutta D, Das S, Samanta D, Senapati S. Skull metastases from carcinoma of cervix: a rare case and review of the literature. $J$ Obstet Gynaecol Res 2010;36:441-3.

10. Abhishek A, Ouseph MM, Sharma P, Kamal V, Sharma M. Bulky scalp metastases and superior sagittal sinus thrombosis from a cervical adenocarcinoma: an unusual case. $J$ Med Imaging Radiat Oncol 2008;52:91-4.

11. Zilberlicht A, Voldavskv E, Lavie O, Auslender R, Shai A. Prolonged survival in a patient with isolated skull recurrence of cervical carcinoma Case report and review of the literature. Gynecol Oncol Rep 2014;11:20-2.

12. Rath GK, Misra BK, Jayalakshmi S. Scalp metastasis of a uterine cervix carcinoma. Obstet Gynaecol Today 2000;8:488-9.

13. Look KY, Brunetto VL, Clarke-Pearson DL, Averette HE, Major FJ, Alvarez RD, Homesley HD, Zaino RJ. An analysis of cell type in patients with surgically staged IB carcinoma of the cervix: A Gynecologic Oncology Group study. Gynecol Oncol 1996;63:304-11. 